\section{Planting Density and Growth Cycle Affect Actual and Potential Latex and Rubber Yields in Taraxacum kok-saghyz}

Griffin M. Bates, Sarah K. McNulty, Nikita D. Amstutz, Victor K. Pool, and Katrina Cornish ${ }^{1}$

Department of Horticulture and Crop Science, and Department of Food, Agricultural, and Biological Engineering, The Ohio Agricultural Research and Development Center, Wooster Campus of the College of Food, Agricultural and Environmental Sciences, The Ohio State University, Wooster, $\mathrm{OH} 44691$

Additional index words. roots, planting boxes, winter

Abstract. Rubber dandelion (Taraxacum kok-saghyz, Rodin) is being developed as a temperate-zone source of rubber, but best agronomic practices must be determined before it can become a viable supplement to imported rubber produced from para rubber tree (Hevea brasiliensis, hevea) plantations located mostly in Southeast Asia. In our study, the effect of planting density and harvest time on yield was determined by transplanting 1.5-month-old greenhouse-produced plants at planting densities of 1.24, 2.47, 4.94, and 9.88 million plants/ha, randomized across four planting boxes with two densities per box (i.e., two planting areas at each density). Half of each planting area was selected randomly and hand-harvested after 6 months, and the remaining plants were hand-harvested after 1 year. Rubber yields per plant were greater after 1 year than after 6 months, but yields per unit area were similar as a result of the loss of half the plants during the severe 2013-14 Ohio winter. A maximum rubber yield of $960 \mathrm{~kg}$ dry rubber/ ha was obtained from the 9.88 million-plants/ha planting density after 1 year, but root size was significantly decreased compared with lower densities, and appeared too small for mechanical harvest. A planting density between 2.47 and 4.94 million plants/ha may produce the optimal combination of root size and total rubber yield. Greater rubber concentrations, faster-growing plants, short-season germplasm, and in-field weed control are required before yields obtained in outdoor planting boxes can be matched or exceeded on farms, especially in a direct-seeded rubber dandelion crop.

Natural rubber is a vital resource for the world economy, being used in more than 50,000 commercial products (Indian Rubber Board, 2013). A relatively high-value agricultural commodity, by the year 2020, the world is expected to suffer a natural rubber supply shortfall of up to 1.5 million metric tonnes, placing the 1.2 million-metric tonnes/ year U.S. import requirement in jeopardy (Accenture, 2014; Statista, 2016). Recently,

Received for publication 20 Feb. 2019. Accepted for publication 14 May 2019.

This work was supported by an Ohio Agricultural Research and Development Center SEED grant, by the Institute of Materials Research at The Ohio State University, and by The Ohio Third Frontier. This work was also supported by the U.S. Department of Agriculture National Institute of Food, Agriculture, Hatch project 230837.

We thank Barbara Hellier for providing the seeds necessary to this work, and Dr. Charles Goebel for his advice on statistical analysis.

This article is a portion of the master's thesis of G.M. Bates, Department of Food, Agricultural, and Biological Engineering.

${ }^{1}$ Corresponding author. E-mail: cornish.19@osu. edu. plants/ha. Photo taken on 8 Oct. 2013 were produced in 2018) occurred compared with demand during 2018 (Association of Natural Rubber Producing Countries. 2019). Currently, the only significant commercial source of natural rubber is the para rubber tree (Hevea brasiliensis Müll. Arg.), grown predominately in tropical Southeast Asia. It has been estimated that 8.4 million ha of new plantations are needed to meet the growing demand for natural rubber, but this will result in disastrous environmental and social consequences to a limited growing area (Edwards et al., 2012; Warren-Thomas et al., 2015). Rubber dandelion (Taraxacum kok-saghyz) also known as russian, siberian, or kazakh dandelion; Buckeye Gold, TK, and TKS - is being domesticated as an alternative source of natural rubber because of its high-molecular weight rubber, excellent physical properties, and adaptation to temperate climates (Cornish et al., 2013; Mooibroek and Cornish, 2000; van Beilen and Poirier, 2007). To advance commercialization, cultural practices must be optimized. In this article, the effect of planting density and growth period on latex and rubber yields in outdoor planting boxes is described.

\section{Materials and Methods}

Planting boxes. One and a half-month-old greenhouse-grown rubber dandelions, produced from seed collected from openpollinated mother plants (which contained 5-7 $\mathrm{mg}$ rubber/g dry weight root, and had an average mature root size of at least $7 \mathrm{~g}$ fresh weight), were transplanted in May 2013 at four densities $(1.24,2.47,4.94$, and 9.88 million plants/ha) into four raised planting boxes at The Ohio Agricultural Research and Development Center in Wooster, $\mathrm{OH}$ (lat. $40^{\circ} 46^{\prime} 20.9^{\prime \prime} \mathrm{N}$, long. $81.93^{\circ} 55^{\prime} 19.4^{\prime \prime} \mathrm{W}$ ). These densities were chosen not only to determine the optimal density, but also to study the effects of overcrowding. Each box was $1.2 \mathrm{~m}$ wide $\times 1.8 \mathrm{~m}$ long $\times 0.6 \mathrm{~m}$ deep and was filled with a mixture of two parts Promix BX
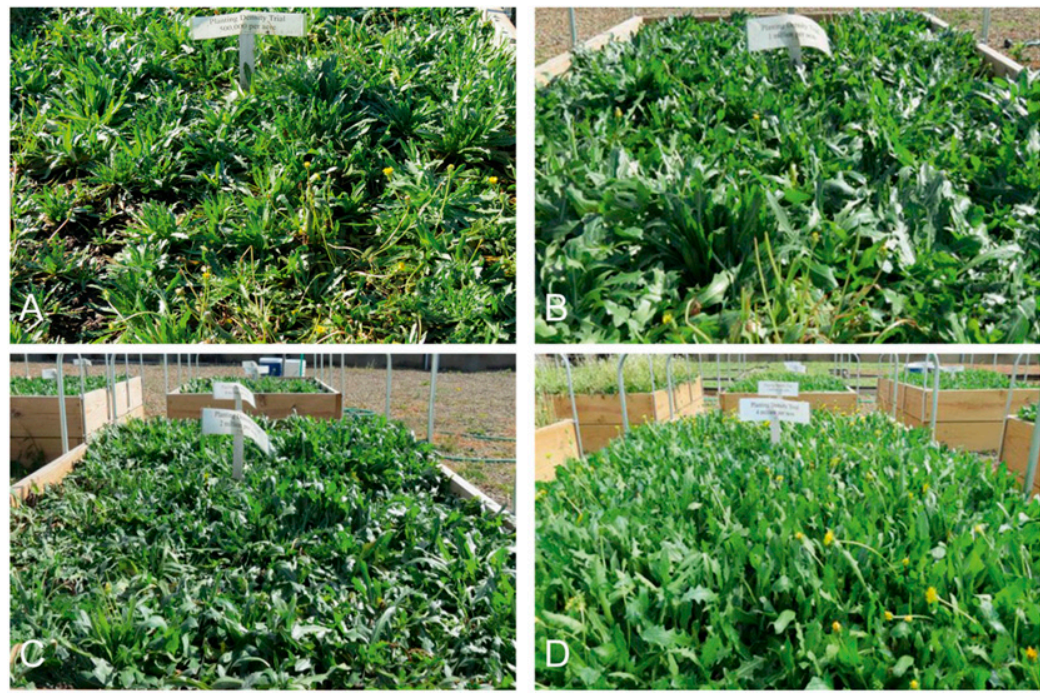

Fig. 1. Plants growing in planting boxes at densities of (A) 1.24, (B) 2.47, (C) 4.94, and (D) 9.88 million 
(Premier Horticulture, Red Hill, PA) and 1 part each of compost, field soil, perlite, and vermiculite to form a light planting medium. Each density was duplicated and assigned randomly to one half of a planting box, resulting in eight total test plots. The number of plants per test plot were 143, 272, 550, and 1110 for the $1.24,2.47,4.94$, and 9.88 million plants/ha densities, respectively. Each test plot was then divided in half (making quarter sections in each box) and assigned randomly to either a 6-month or 1-year harvest. Plants were watered as necessary (up to daily) and fertilized every third watering with $150 \mathrm{ppm}$ 20-20-20 fertilizer. All boxes were frequently hand-weeded to eliminate weed pressure as a variable. During the winter months, the boxes were covered with cloches made from 0.15$\mathrm{mm}$ clear plastic sheeting (Klerks Hyplast, Chester, SC). After 6 months (Oct. 2013), two quarter sections were hand-harvested. The remaining quarter sections were harvested in May 2014 (after 1 year). For each quarter section, all plants were counted, and fresh plant and root weights of each plant were recorded. The roots from quarter section pairs with the same planting density were then pooled, separated evenly into five groups by size, and 15 samples were collected by selecting three plants randomly from each size class. Latex and rubber contents were determined for each plant (described later). Selected plants were placed in sealed zippered bags between layers of moist paper towels and were stored at $4{ }^{\circ} \mathrm{C}$ in the dark for up to 1 week until processing.
Latex quantification. Reagents were purchased from Fisher Scientific (Waltham, MA). A published latex quantification method (Cornish et al., 1999) was modified for use with rubber dandelion roots as follows. Each root sample was homogenized in $0.2 \% \mathrm{NH}_{4}-$ $\mathrm{OH}$ ( $\mathrm{pH} 10)$, made with distilled water, using a 37-mL blender (model MC1; Waring Laboratory Science, Torrington, CT) for samples less than $7 \mathrm{~g}$ fresh weight, a 110 $\mathrm{mL}$ blender (model MC2, Waring Laboratory Science) for samples between 7 and $15 \mathrm{~g}$, and a 1.2-L blender (model CAC32; Waring Laboratory Science) for samples more than $15 \mathrm{~g}$ fresh weight. Samples were ground for $45 \mathrm{~s}$ in the MC1 blender, $25 \mathrm{~s}$ in the $\mathrm{MC} 2$ blender, and $15 \mathrm{~s}$ in the CAC32 blender. These grinding times were determined from preliminary experiments using grinding time courses to determine the duration needed for complete extraction of rubber particles [as described for guayule in Cornish et al. (1999)]. Latex was quantified as described previously (Bates and Cornish, 2018). Homogenate was transferred to medium-size weigh boats (top diameter, $67 \mathrm{~mm}$ ) (Fisherbrand, Fisher Scientific) and placed in a $50{ }^{\circ} \mathrm{C}$ drying oven until completely dry. Residual rubber was then quantified gravimetrically by accelerated solvent extraction (see next section).

Accelerated solvent extraction. Accelerated solvent extraction (ASE) (Luthria et al., 2004) was used to quantify rubber content, similar to part of a published procedure (Ramirez-Cadavid et al., 2017), with modifi-

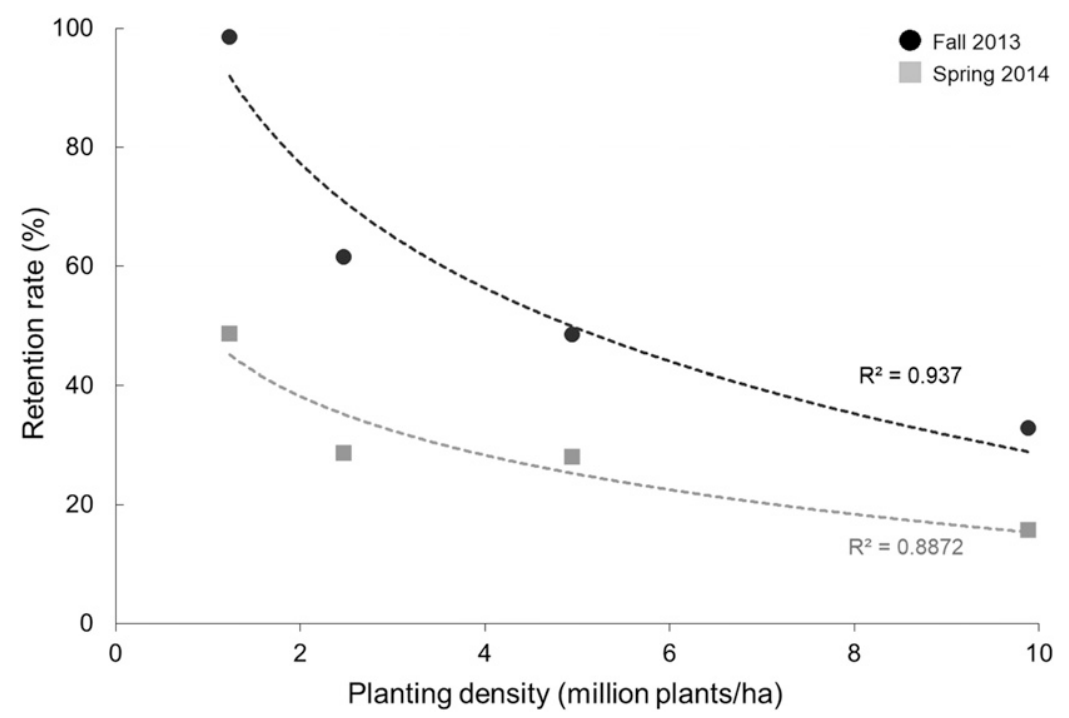

Fig. 2. Plant retention rates 6 months (black circle) and 1 year (gray square) after transplanting in May 2013. The total number of plants harvested is expressed as a percentage of the original number of transplants. Trend lines are logarithmic and $r^{2}$ values are reported. cations required to shorten the analytical procedure and permit larger sample numbers to be analyzed. The dried homogenized root samples were finely ground using an analytical mill (IKA 11 basic; IKA, Wilmington, $\mathrm{NC}$ ) for $10 \mathrm{~s}$ or until sample uniformity was achieved by visual estimation. Subsamples weighing $0.2500 \pm 0.0005 \mathrm{~g}$ were mixed with $15 \mathrm{~g}(\approx 1.5 \mathrm{tsp})$ of inert Dionex Ottawa sand (20-30 mesh) (Fisher Scientific) to distribute the sample evenly within an 11-mL stainless steel extraction cell (Dionex; Thermo Fisher Scientific, Waltham, MA). Cellulose filter paper $(19.8 \mathrm{~mm})$ (Thermo Fisher Scientific) was placed at the bottom of the cell, the sample and sand mixture was poured into the cell, and a cellulose filter paper was placed on top to prevent clogging of the machine. Twenty-three cells, plus a blank cell filled with inert Ottawa sand only, were loaded into the upper carousel of a Dionex accelerated solvent extractor (ASE 200; Thermo Fisher Scientific). Hexane was added sequentially to each cell, then pressurized to $10.34 \mathrm{MPa}(1500 \mathrm{psi})$ and heated to $120{ }^{\circ} \mathrm{C}$ for a 50 -min cycle that included two 20-min static periods and two repeated $60-\mathrm{s}$ purges. The hexane extracts were collected into sample-specific $60-\mathrm{mL}$ glass collection vials (Thermo Fisher Scientific) in the lower carousel. The vials were vortexed and decanted into preweighed 60$\mathrm{mL}$ aluminum pans (Fisherbrand, Fisher Scientific). The pans were dried overnight at ambient temperature in a fume hood. After $24 \mathrm{~h}$, the aluminum pans with dry analyte were weighed. The total extractable rubber content was determined by subtracting $15.22 \mathrm{mg} / \mathrm{g}$ root dry weight from the hexane extracts to adjust for nonrubber compounds coextracted by the hexane. This correction factor was determined from sequential acetone and hexane accelerated solvent extraction of 79 root samples. The acetone extracts contained $15.22 \pm 0.486$ (SE) $\mathrm{mg} / \mathrm{g}$ root dry weight.

Statistical analysis. Data were analyzed using three-way analyses of variance (ANOVAs) in $\mathrm{R}$ version 3.5.2 (R Development Core Team, Vienna, Austria), and significance was claimed at $P$ values of 0.05 and less. Latex/rubber ratios were calculated for individual plants, and these ratios were used as individual data points in analyses of variance.

\section{Results}

Planting boxes. Healthy plant growth was maintained throughout the first 6 months (Fig. 1). All densities completely covered the soil. As density increased, rosettes became more vertical and the plants became

Table 1. Table of plant retention rates at the Oct. 2013 and May 2014 harvests.

\begin{tabular}{llll}
\hline & \multicolumn{3}{c}{ Planting density (million plants/ha) } \\
\cline { 2 - 4 } Retention rate (\%) & 1.24 & 2.47 & 4.94 \\
\hline At 6-mo. harvest & 98.6 & 61.6 & 48.5 \\
Between 6- and 12-mo. harvest & 49.3 & 46.5 & 57.7 \\
At 12-mo. harvest & 48.6 & 28.6 & 32.8 \\
\hline
\end{tabular}




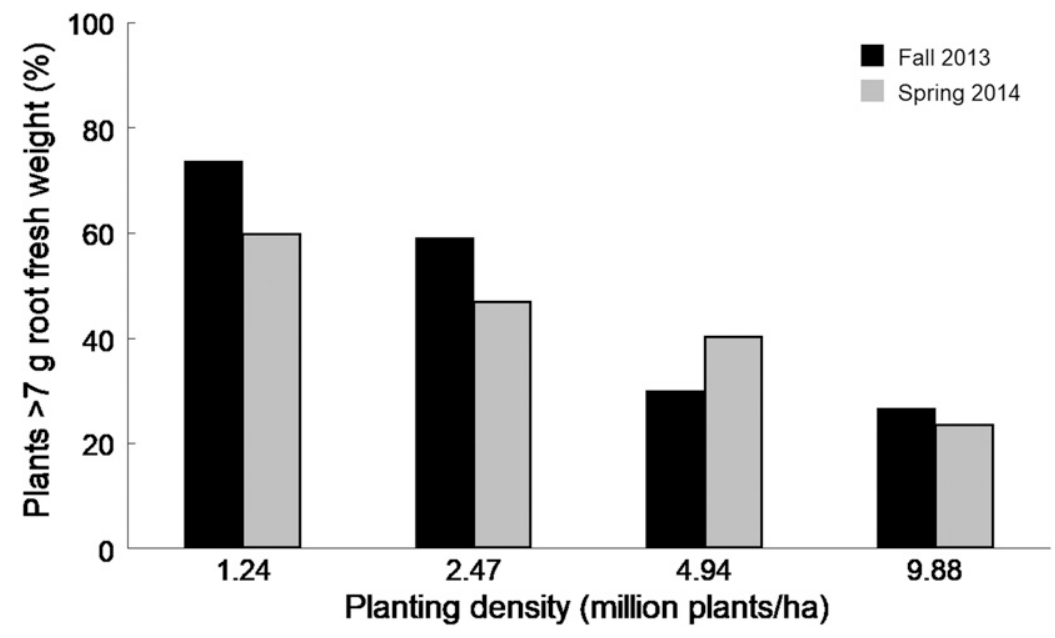

Fig. 3. Percentage of plants with a root weight greater than $7 \mathrm{~g}$ harvested from two $0.28-\mathrm{m}^{2}$ quarter sections of each planting density after 6 months (black) and 1 year (gray).

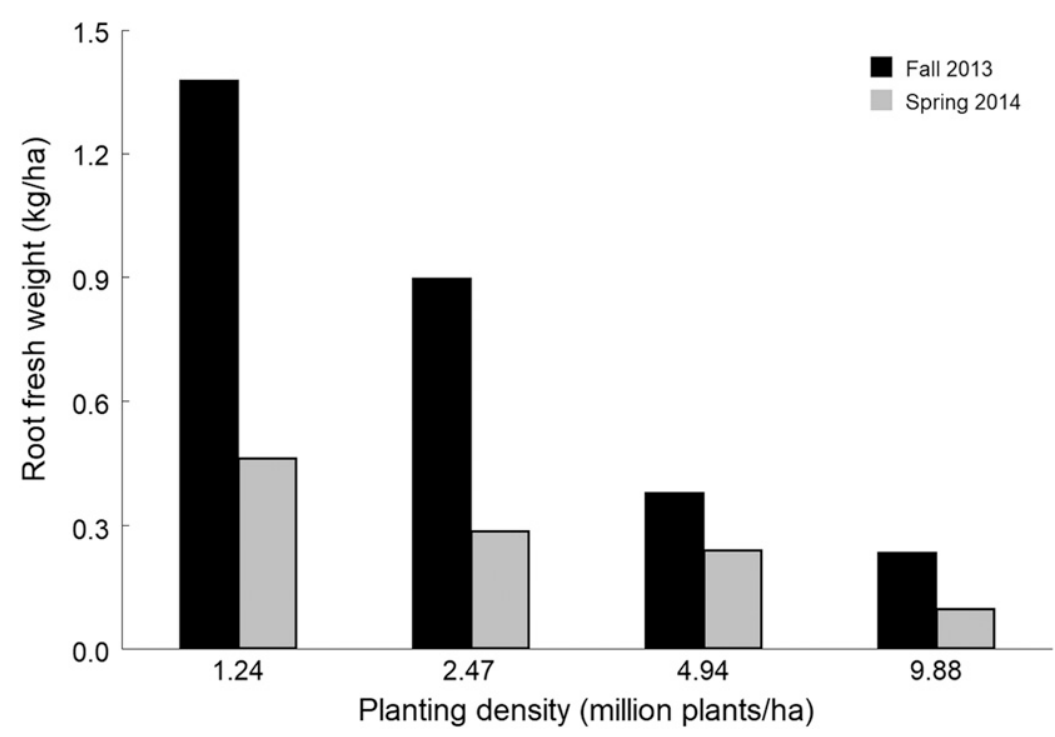

Fig. 4. Total root weight of all roots harvested and the mean from two $0.28-\mathrm{m}^{2}$ quarter sections of each planting density after 6 months (black) and 1 year (gray).

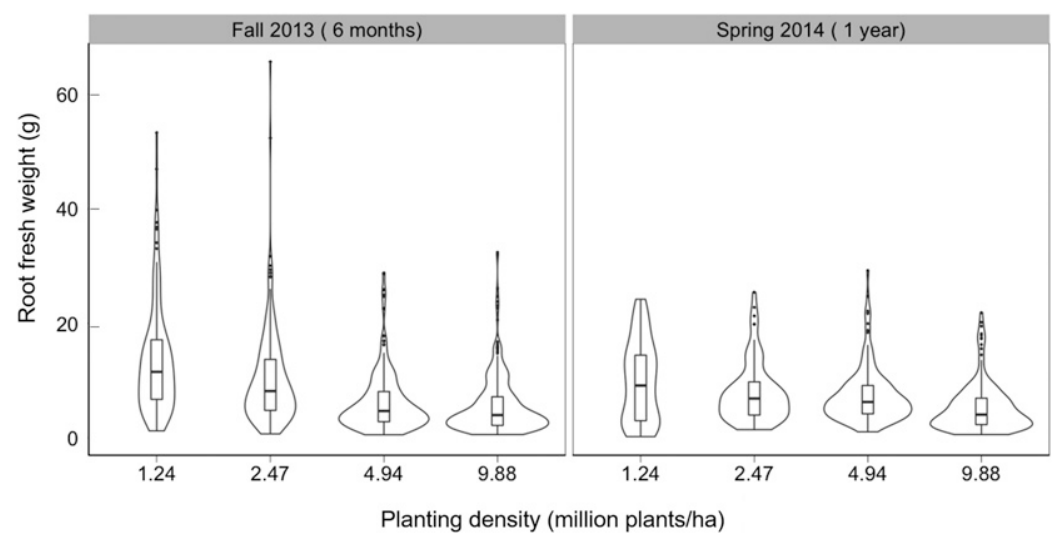

Fig. 5. Violin plots of Fall 2013 and Spring 2014 harvested rubber dandelion roots. The wide areas of the plot correspond to a high frequency of roots whereas the narrow areas indicate smaller amounts of roots of that size. Each individual box plot within the violin plot represents the inner second and third quartile, with the division of these boxes being the median root fresh weight. Bars extending from the boxes represent the lower and upper quartiles for root weight. Solid points represent outliers. smaller-effects most obvious at the highest density of 9.88 million plants/ha (Fig. 1D).

Survival rates. Plant numbers decreased as planting density increased (Fig. 2) during the first and second 6-month periods in the boxes. Roots harvested from the lowest planting density of 1.24 million plants/ha retained virtually all plants during the initial 6-month growing season $(98.6 \%$ retention, Table 1). As expected, the extent of "selfthinning" increased significantly with planting density (increased competition), with only $32.8 \%$ remaining in the highest density by the 6-month harvest. However, the number of surviving plants still increased with planting density (Fig. 2). Half the plants survived the winter, with all planting densities suffering a similar degree of loss (Table 1). Plants from highest original plant density of 9.88 million plants/ha had the poorest overall survival rate, retaining only $15.7 \%$ of plants (Fig. 2, Table 1). A threeway ANOVA, with harvest time, planting density, and position of harvested plants in the boxes as main effects, indicated that harvest time $(P=0.0021)$ and planting density $(P=0.0018)$ only affected plant retention significantly in the boxes.

Root size. Root size affects harvestability from field soil. Roots that are too small to be machine-harvested are lost. A fresh root weight of $7 \mathrm{~g}$ was set as the minimum desired root size because these roots can be harvested mechanically and previous research has found that roots with a fresh weight of more than $7 \mathrm{~g}$ are capable of cold-induced rubber biosynthesis in postharvest storage (Cornish et al., 2013). A three-way ANOVA, with harvest time, planting density, and position of harvested plants in the boxes as main effects, indicated that the percentage of harvested roots with a fresh root weight greater than $7 \mathrm{~g}$ decreased significantly with increasing planting density $(P=0.0014$, Fig. 3$)$, but no other effects were significant.

Across all densities, total freshly harvested root weights were significantly greater after 6 months than after 1 year $(P=1.87 \mathrm{E}$ 05, Fig. 4). This is because the roots lost weight as their storage carbohydrates (Ramirez-Cadavid et al., 2017) were catabolized during the winter, and the largest rooted plants were lost preferentially during the winter (Fig. 5). It is also possible that some root death occurred in surviving plants, although this could not be quantified. Some roots on the 12-month-old plants harvested in Spring 2014 may have been newly grown, but these also could not be quantified. A threeway ANOVA revealed no other significant effects.

Latex and rubber content. Total (or combined) rubber content (the sum of the latex and solid rubber fractions) was similar across all planting densities. However, total rubber content and latex concentration were significantly greater after 1 year than after 6 months $(P=8.58 \mathrm{E}-14$ and $P=$ 0.005 , respectively; Fig. 6). The three-way ANOVA revealed no other significant effects, but latex concentration appeared to decrease 


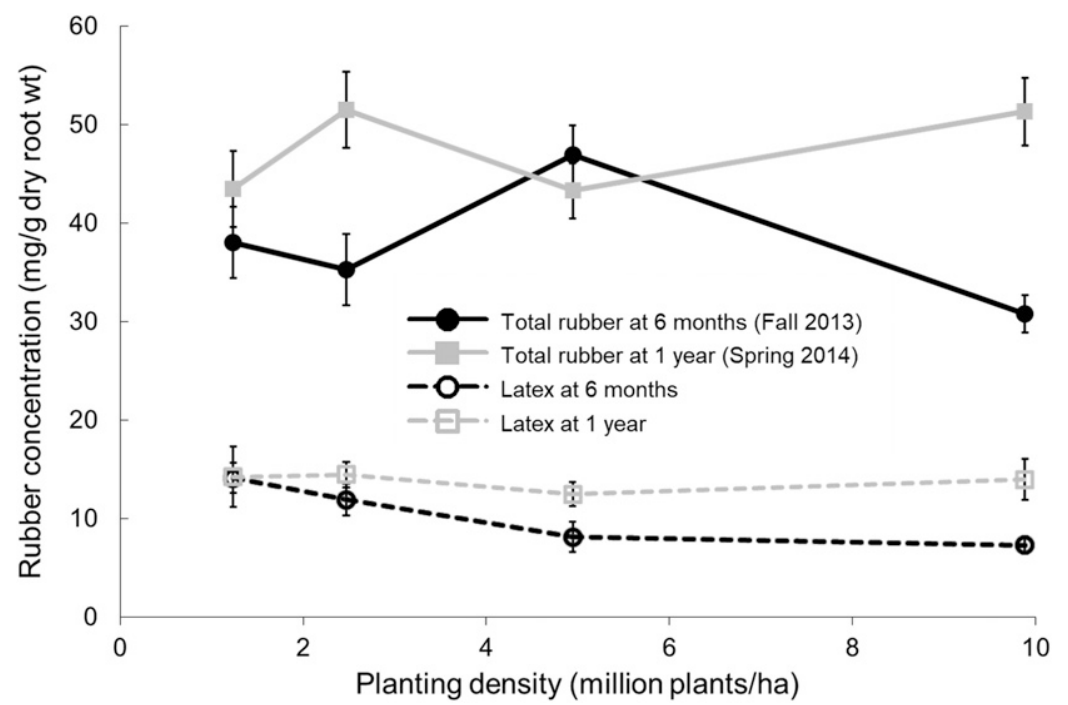

Fig. 6. Total rubber (rubber + latex) (solid lines) and latex concentration (dashed lines) in roots harvested from two $0.28-\mathrm{m}^{2}$ quarter sections of each planting density after six months ( $\left.\longrightarrow-,-\mathbf{O}-\right)$ and one year $(\square,--\square--$ ). Values are the means of 15 randomly selected samples \pm SE.

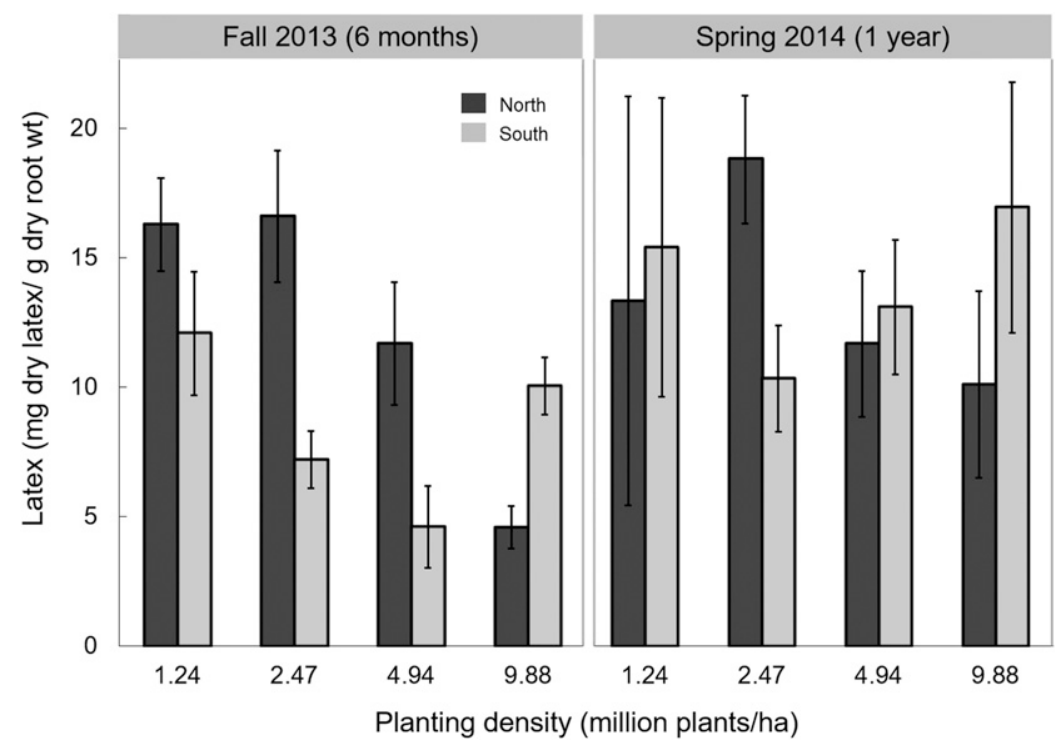

Fig. 7. Effect of position of quarter sections, within the boxes, on extractable latex content in roots harvested after 6 months and 1 year from the northern (dark bars) and southern (light bars) end of the planting boxes. Values are the means of 15 samples \pm SE.

slightly with increasing planting density $(P=$ 0.0746, Fig. 6).

However, latex concentration decreased significantly as planting density increased $(P=0.0103)$. It was most pronounced during the first growing season and was less in the southern part of the boxes $(P=0.0005)$, suggesting a temperature effect (Fig. 7). The interaction of plant density and location within the boxes also had a significant effect on latex concentration $(P=0.0005)$.

Because all rubber originates as latex, the effects of planting density on the ratio of latex and rubber within the roots were determined. Harvest season had the most significant effect on the proportion of latex $(P=2.54 \mathrm{E}-4$, Fig. 8). The greatest proportion of latex to rubber was seen in the 2.47 million-plants/ha the 9.88 million-plants/ha planting density (Fig. 9). The only statistically significant factor affecting total harvestable rubber was planting density $(P=0.0066$, Fig. 9$)$.

\section{Discussion}

The current study was performed in outdoor planting boxes to share most of the environmental conditions with the nearby fields while limiting edaphic variation and eliminating weed pressure. Planting density is particularly important in field-grown $T$. kok-saghyz because its leaves grow as rosettes just above the soil surface. Getting a field crop to the stage of complete soil coverage requires chemical weed control while the plants are very young, and it remains the primary obstacle to field production. The greater the planting density, the faster the soil can be covered by expanding rosettes, and the earlier natural weed suppression occurs. However, if the planting density is too high, plant size is reduced too much and harvestable product (the roots) is lost. Thus, determining the optimal balance between rubber yield (harvestable roots $x$ rubber concentration) and planting density is essential.

Planting density strongly affected the overall rubber yield of rubber dandelion roots, but this was caused primarily by variation in root size, not rubber concentration, which did not vary much with root size. Also, although the amounts of latex and rubber varied with harvest time and planting density, none of the plants had more than $40 \%$ of their rubber in latex form, and some had less than $10 \%$ (Fig. 8). The conversion of latex (aqueous emulsion of rubber particles) into solid rubber within living tissues can be induced by freeze-thaw cycles (Bates and Cornish, 2018), but the mechanism underlying rubber particle coagulation during the growing season is not yet understood. Nevertheless, this behavior means that this species is not currently a good candidate for latex production, but rather a source of solid rubber. The latex phase can be converted to the solid form by root drying, after which all the rubber can be extracted by a single process (Ramirez-Cadavid et al., 2017).

During the winter season of 2013-14, Wooster, $\mathrm{OH}$, experienced extraordinarily low air temperatures, with minimum temperatures dropping to less than $-26{ }^{\circ} \mathrm{C}$, with a total of $53 \mathrm{~d}$ when the maximum air temperature was less than $0{ }^{\circ} \mathrm{C}$ and $131 \mathrm{~d}$ when the minimum air temperature dropped to less than $0{ }^{\circ} \mathrm{C}$ (Fig. 10). The average daily soil temperature, at a depth of $10.2 \mathrm{~cm}$, was less than $0{ }^{\circ} \mathrm{C}$ for 53 of 54 consecutive days from 23 Jan. 2014 to 17 Mar. 2014 (Fig. 11). Half of the plants in the boxes, and in a 1-acre nearby field (data not shown), survived these extreme temperatures. Survival was not dependent on crowding or plant size, in general, because the majority of self-thinning occurred before the winter season, and all densities - and therefore sizes - experienced similar rates of overwinter death. However, 


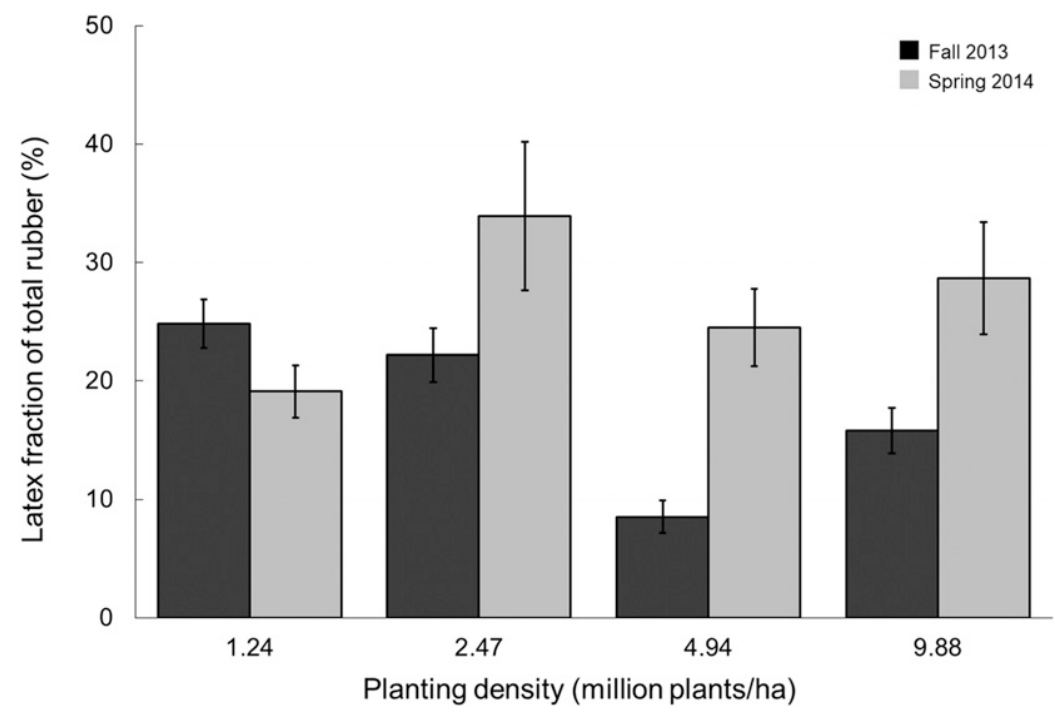

Fig. 8. The percentage of rubber in the form of latex in the roots for two $0.28-\mathrm{m}^{2}$ plots after 6 months (black) and 1 year (gray). Percentages were calculated as [Latex/(Latex + Residual solid rubber)] $\times$ 100. Values are for random samples from complete harvests and are reported as mean \pm SE.

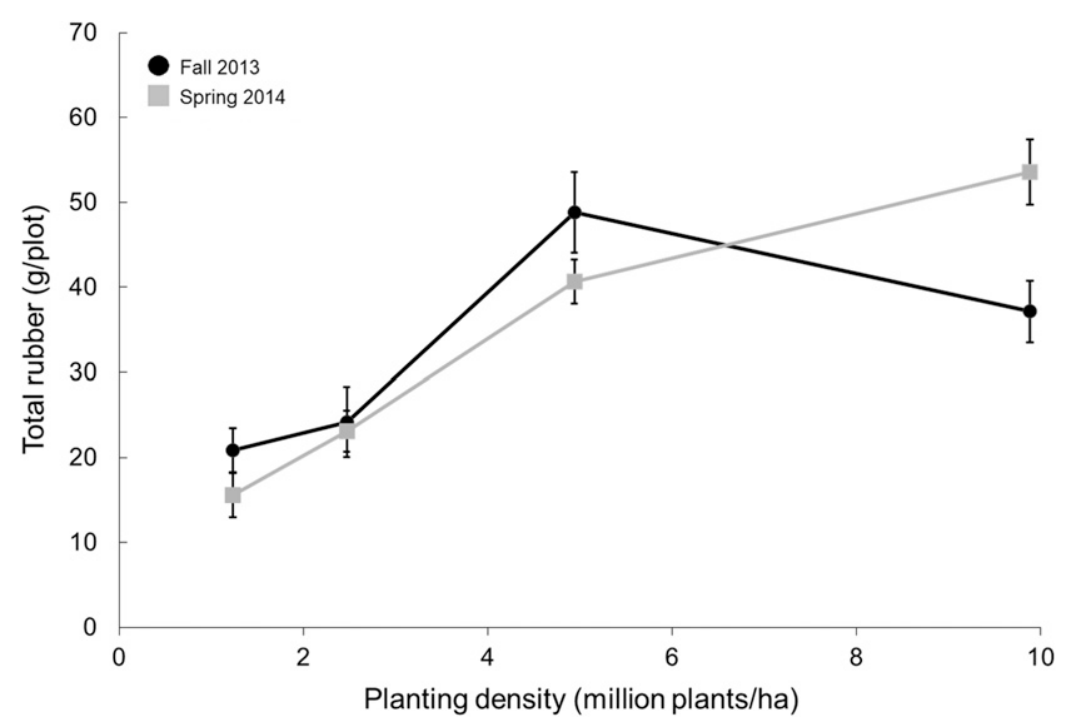

Fig. 9. Total combined rubber harvestable averaged for two experimental plots harvested after 6 months (—) and 1 year (— Values are the mean of up to 15 samples for combined rubber per root multiplied by the number of harvested roots \pm SE of plants selected randomly from a complete harvest of a $0.28-\mathrm{m}^{2}$ plot.

plants with the largest roots appeared to be lost preferentially during the winter because they were more abundant at 6 months than after 1 year (Fig. 5). The ability of half the plants to survive these extreme conditions supports the potential of this species as a crop for northern countries with harsh winters.

Establishing a crop using transplants, as used in our study, is expensive, and commercially viable rubber dandelion will need to be direct-seeded. However, direct seeding would shorten the growing period by about 2 months (because the transplants are grown in greenhouses before the planting season), makes weed control even more challenging (because seedlings are slow to take off), and means that an autumn harvest should occur as late in the year as possible. Until short-season germplasm is developed, a direct-seeded crop in Ohio, or similar geographies, encourages the overwintering agricultural model investigated in this study.

Previous studies have shown that some autumn-harvested fresh roots weighing more than $7 \mathrm{~g}$ can double their rubber content when stored postharvest in natural (root cellar) or controlled $\left(8^{\circ} \mathrm{C}\right)$ cold conditions (Cornish et al., 2013). Thus, when only roots greater than $7 \mathrm{~g}$ fresh weight were counted (Fig. 3), it seems possible that autumnharvested roots placed in cold storage for 15-60 d (depending on the temperature) could produce 600 to 1200 dry kg natural rubber/ha (Fig. 12). Hevea rubber plantations range in productivity from 800 to $1100 \mathrm{~kg}$ dry natural rubber/ha/year (Sopheaveasna et al., 2008).
The weed-free, outdoor planting boxes, with controlled fertigation and light medium, provided a more favorable growing environment than most fields. Although this study grew largely unimproved germplasm with a maximum rubber concentration of $\approx 50 \mathrm{mg} / \mathrm{g}$ dry root (Fig. 6), transplants could produce 400 to $900 \mathrm{~kg}$ natural rubber/ha in 6 months, without overwintering (Fig. 12, dark-gray filled circles). Overwintered (May-harvested) plants could yield upward of $1000 \mathrm{~kg}$ dry rubber/ha (Fig. 12, gray squares). Many individual plants in our collection have more than twice this rubber content (Cornish et al., 2016; and data not shown), and it seems likely that germplasm bred for greater rubber concentration and large size would offset the expected lower field performance (even in weed-free fields), and may allow rubber production levels comparable to those achieved in the planting boxes.

The rubber yields per hectare projected from the planting box data in this study are much greater than those reported in other recent studies (Arias et al., 2016; Eggert et al., 2018; Kreuzberger et al., 2016). However, these studies generally had very low planting densities, at 240,000 plants/ha (Arias et al., 2016); 60,000 plants/ha and 1.2 million plants/ha (Kreuzberger et al., 2016); and $88,889,133,333$, and 222,222 plants/ha (Eggert et al., 2018). In addition, the rubber concentrations were low. Poor field emergence (of sown crop) and poor survivability of seedlings and transplants contributed to the very low rubber yields-per-hectare reported. The outdoor planting boxes used in our study, which provided a more controlled environment, and a less dense growing medium, demonstrated that much greater planting densities are required than those reported in the studies just mentioned, but they have not yet been tested in the field.

The climate and field conditions of Wooster, OH (midwestern United States), are very similar to many agricultural climate zones around the world, including parts of Canada, China, and Europe (Food and Agriculture Organization of the United Nations \& UNESCO, 2003), with mild summers, cold winters, and a growing season typically from April or May to October (Joint Agricultural Weather Facility, 1994). In addition, with a growing season that can be cut short by early snow, rubber dandelion's potential to produce additional rubber during postharvest storage in barns and root cellars (Cornish et al., 2013, 2016) could be especially beneficial to growers until vigorous, short-season germplasm is fully developed. However, it is currently not possible to produce plants with roots of at least $7 \mathrm{~g}$ fresh weight, even from a lowdensity, direct-seeded crop in Ohio, when grown as an annual because of the short season. Thus, high-density planting, overwintering, and harvest in the spring or early summer seems the likely best practice for direct-seeding current germplasm in Ohio. An annual direct-seeded crop could be 


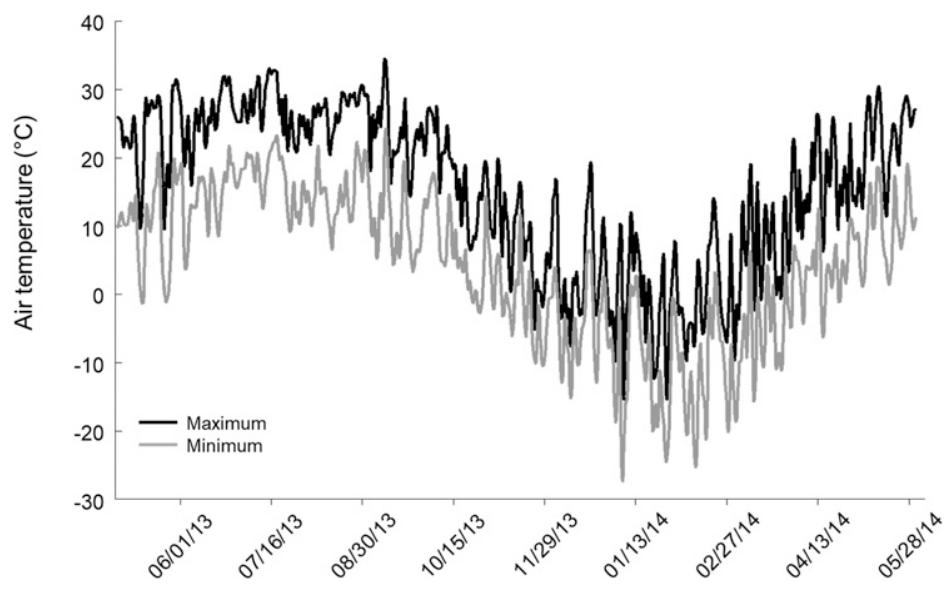

Fig. 10. Daily maximum (black line) and minimum (gray line) air temperatures at the National Oceanic and Atmospheric Administration Wooster Experimental Research Station (lat. 40 46' 20.9"N, long. 81.93 $\left.55^{\prime} 19.4^{\prime \prime W}\right)$ in Wooster, OH, from 1 May 2013 through 31 May 2014.

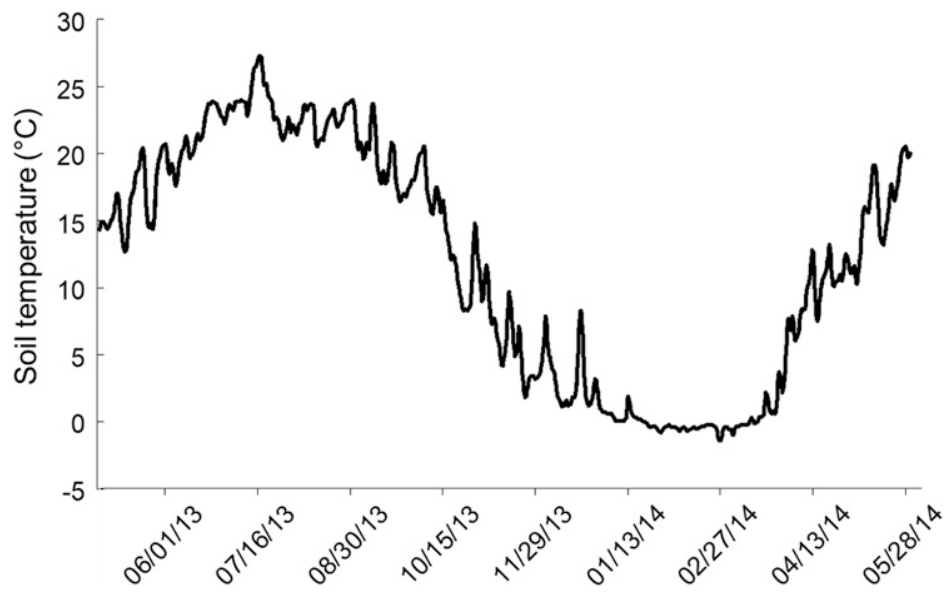

Fig. 11. Daily soil temperature at a 10-cm depth in Wooster-Riddles silt loam soil at the National Oceanic and Atmospheric Administration Wooster Experimental Research Station (lat. 40 46'20.9"N, long. 81.93 $\left.55^{\prime} 19.4^{\prime \prime} \mathrm{W}\right)$ in Wooster, OH, from 1 May 2013 through 31 May 2014.

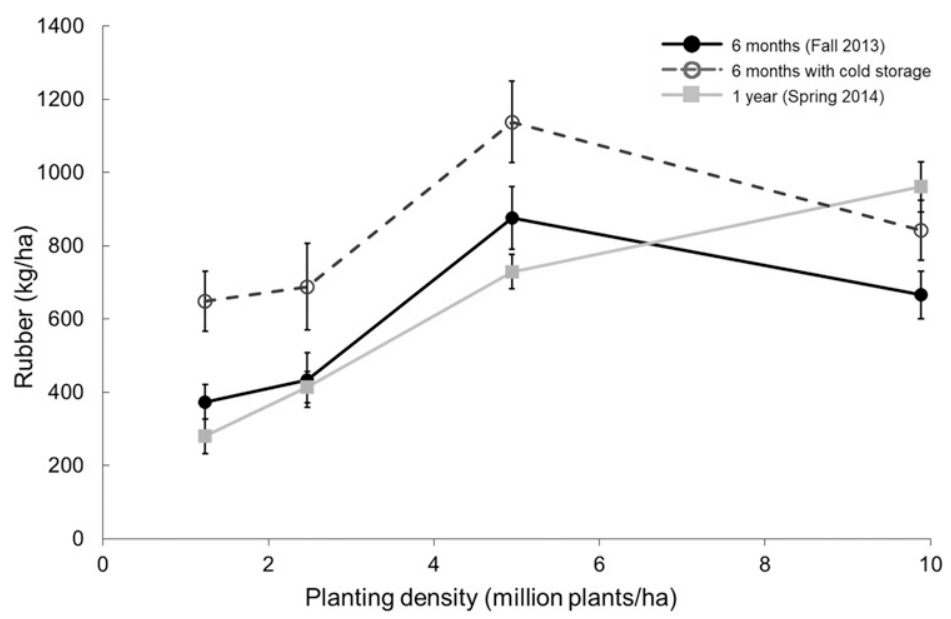

Fig. 12. Predicted rubber yields from three agricultural management systems all begun with a May transplanting date. Growth cycles: 1 year (- $\square$ ), 6 months (—-), and 6 months with a 60 -day postharvest cold storage (- - - ) of roots weighing more than $7 \mathrm{~g}$ fresh weight. Values are based on the amount of harvestable rubber in $0.28-\mathrm{m}^{2}$ plots in planting boxes extrapolated to a full hectare. The cold-storage values are based on roots greater than $7 \mathrm{~g}$ fresh weight doubling their rubber content postharvest.

grown in regions with a longer (at least 8month) growing season.

In conclusion, rubber dandelion has the potential to provide an economically viable amount of harvestable rubber when grown at high planting densities of at least 4.94 million plants/ha as an annual crop, and at least 9.88 million plants/ha if overwin- tered. However, greater rubber concentrations, faster-growing plants, short-season germplasm, and in-field weed control are still required before yields obtained in outdoor planting boxes can be matched or exceeded by farms in areas with severe winters.

\section{Literature Cited}

Accenture. 2014. Extracting value from natural rubber trading markets: Optimizing marketing, procurement and heading for producers and consumers: Accenture Strategy.

Arias, M., J. Herrero, M. Ricobaraza, M. Hernandez, and E. Ritter. 2016. Evaluation of root biomass, rubber and inulin contents in nine Taraxacum kok-saghyz Rodin populations. Ind. Crops Prod. 83:316-321.

Association of Natural Rubber Producing Countries. 2019. ANRPC Releases natural rubber trends \& statistics, Dec. 2018. 13 May 2019 $<$ http://www.anrpc.org/html/news-secretariatdetails.aspx?ID=9\&PID=39\&NID=2271>

Bates, G.M. and K. Cornish. 2018. Rapid and complete removal of guayule (Parthenium argentatum) leaves by cryodefoliation, and freeze and thaw induction of rubber particle coagulation. Ind. Crops Prod. 125:491-495.

Cornish, K., G.M. Bates, S.K. McNulty, S.E Kopicky, S. Grewal, J. Rossington, F.C. Michel, Jr., S. Walker, and M.D. Kleinhenz. 2013. Kazak dandelion storage: A study into rubber production in Taraxacum kok-saghyz with an emphasis on post-harvest storage. USA Tire Technol. Intl. 10:36-38.

Cornish, K., M.H. Chapman, F.S. Nakayama, S.H Vinyard, and L.C. Whitehand. 1999. Latex quantification in guayule shrub and homogenate. Ind. Crops Prod. 10:121-136.

Cornish, K., S.L. Kopicky, S.K. McNulty, N. Amstutz, A.M. Chanon, S. Walker, M.D Kleinhenz, A.R. Miller, and J.G. Streeter. 2016. Temporal diversity of Taraxacum koksaghyz plants reveals high rubber yield phenotypes. Biodiversitas 17:847-856.

Edwards, D.P., B. Fisher, and D.S. Wilcove. 2012 High conservation value or high confusion value? Sustainable agriculture and biodiversity conservation in the tropics. Conserv. Lett. $5(1): 20-27$.

Eggert, M., J. Schiemann, and K. Thiele. 2018. Yield performance of Russian dandelion transplants (Taraxacum kok-saghyz L. Rodin) in flat bed and ridge cultivation with different planting densities. Eur. J. Agron. 93:126134.

Food and Agriculture Organization of the United Nations \& UNESCO. 2003. Digital soil map of the world and derived soil properties. Food and Agriculture Organization, Rome, Italy.

Indian Rubber Board. 2013. Indian rubber statistics. Ministry of Commerce and Industry, Government of India.

Joint Agricultural Weather Facility (U.S.). 1994. Major world crop areas and climatic profiles. U.S. Department of Agriculture, World Agricultural Outlook Board, Joint Agricultural Weather Facility, Washington, DC.

Kreuzberger, M., T. Hahn, S. Zibek, and J. Schiemann. 2016. Seasonal pattern of biomass and rubber and inulin of wild Russian dandelion (Taraxacum kok-saghyz L. Rodin) under experimental field conditions. Eur. J. Agron. 80:66-77.

Luthria, D.L., D. Vinjamoori, K. Noel, and J. Ezzel. 2004. Accelerated solvent extraction. In: Oil extraction and analysis: Critical issues 
and comparative studies. The American Oil Chemists Society, Champaign, IL.

Mooibroek, H. and K. Cornish. 2000. Alternative sources of natural rubber. Appl. Microbiol. Biotechnol. 53:355-365.

Ramirez-Cadavid, D.A., K. Cornish, and F.C. Michel, Jr. 2017. Taraxacum kok-saghyz (TK): Compositional analysis of a feedstock for natural rubber and other bioproducts. Ind. Crops Prod. 107:624-640.
Sopheaveasna, M., S. Chinsathit, A. Pookpakdi, and P. Kasemsap. 2008. The effect of fertilizer and irrigation on yield and quality of rubber (Hevea brasiliensis) grown in Chanthaburi Province of Thailand. Kasetsart Journal - Natural Science 42(2):226-237.

Statista. 2016. Global natural rubber production from 2000 to 2015 (in 1,000 metric tons). van Beilen, J.B. and Y. Poirier. 2007. Establishment of new crops for the production of natural rubber. Trends Biotechnol. 25:522529.

Warren-Thomas, E., P.M. Dolman, and D.P. Edwards. 2015. Increasing demand for natural rubber necessitates a robust sustainability initiative to mitigate impacts on tropical biodiversity. Conserv. Lett. 8:230-241. 